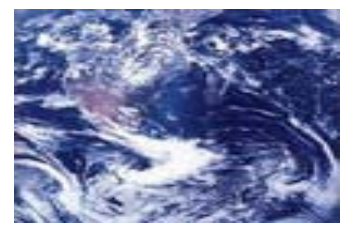

International Review of Research in Open and Distance Learning

ISSN: 1492-3831

Volume 6, Number 1.

March - 2005

\title{
Book Review - Vocational Education and Training through Open and Distance Learning
}

Editors: Louise Moran and Greville Rumble (2004). Vocational Education and Training through Open and Distance Learning. 238 pages, softcover. Commonwealth of Learning and RoutledgeFalmer Press: London and New York. ISBN: 0415345243

Reviewed by: Zane L. Berge, University of Maryland, Baltimore County, USA

The increasing pace of change, combined with the exponential increase in knowledge-work and the growing numbers of persons worldwide in the workplace, all challenge the capabilities of training and education resources to effectively and efficiently develop the human capital needed by organizations to sustain and compete. Traditional, face-to-face training has often proved inadequate in meeting the challenges that staffing the workplace has presented. During the past two decades, open and distance learning is one of the ways trainers and educators have increasingly been using to help train and educate workers.

As more workers become part of knowledge-driven and knowledge-based world economies, the premise of the book edited by Moran and Rumble is that our traditional systems of delivering training will continue to fall short of meeting the current and anticipated demands for rapid and efficient workforce preparation. While successful initiatives in open and distance education have been useful and valuable, Gajaraj Dhanarajan, president and CEO of The Commonwealth of Learning, pointed out in the Forward to the book that "these ventures have been carried out by the enthusiasm of individuals, departments of larger institutions and in some rare occasions by clearly enunciated policy directives from governments" (p. xi). It is the contention of Dhanarajan that when there are unambiguous policy directives for open and distance learning, initiatives have met with considerable success. Without such clear policy directives, however, training and education efforts have often been characterized by high failure rates. It is with this in mind that editors Moran and Rumble have produced a book with contributions from some of the pioneers in online vocational education and training (VET). Taken together, the book has a great deal to say to policy makers and government planners who are developing policy to develop human capital in the workplace. A broad definition of policy used here is that it provides a framework for operations using an agreed upon set of guidelines that explain the roles and responsibilities of the participants (Gellman-Danley and Fetzner, 1998).

In Chapter 1, the editors set the stage by defining VET as "the acquisition of knowledge, skills and competences for job performance" (p. 3). They point out that VET is not a term that is 
universally used, and that depending upon the country or region of the world, other terms can be substituted, for example, "further education and training," "technical and vocational education and training," "technical education,” etc. The editors also explore answers to the general questions of why VET is important and to whom, how VET is organized, and where does distance education fit into the equation. At the root of these questions is the educational philosophy and beliefs of the person answering them about what the purposes of education. As the age-old debate about the difference between a "liberal" and a "utilitarian" education continues, the authors point out that over the last 30 years, policy makers and politicians have argued that the real purpose of education is to prepare people for the world of work, and to promote economic growth. Within that context, certainly VET can be an important stepping stone in furthering this mission.

The seeming interchangeability of the terms distance learning and distance education as used in the book is disconcerting. Education indicates a formal, institutionally sponsored activity, whereas learning is what students do. I would have preferred the book to be titled, Vocational Education and Training through Open and Distance Education, since it discusses policy and planning of formal educational programs with little direct attention to student learning.

The authors finish the first chapter noting that distance education is complex to design and deliver (Berge 2004), and not necessarily less expensive than traditional forms of education. Still, there are a dozen benefits of distance education and training to organizations other than the purely economic, such as reduction in the amount of worker time spent away from the job, content that can be updated more easily resulting in better quality, and it allows organizations to obtain, manage, and disperse knowledge quickly throughout their enterprise (e.g., Kruse 2003; Massy and Zemsky 2003; ThinQ Research Department n.d.; W.R. Hambrecht \& Co. 2001). Those who implement and set policy for distance education must balance the challenges against the benefits.

\section{International VET}

Chapters 2, 3, and 4 explore distance education models enabling vocational education to be provided internationally. In Chapter 2, Magdaleen Juma of the African Virtual University explores the model through which VET is being provided to workers in the countries of the subSaharan Africa. In Chapter 3, David Murphy draws on his experience in Hong Kong, Australia, and other countries to summarize the major planning and implementation issues faced by designers and developers. Vivien Martin shows in Chapter 4, how VET materials developed for workplace training in one country can be repurposed and adapted for use in another country.

Why is international VET needed? Why endure the added complexity and cultural tumult that often accompanies such efforts? According to Juma, tertiary institutions are overwhelmed with problems related to access, finance, quality, and internal and external efficiency. Essentially, "existing universities cannot meet existing levels of demand: there are too few trained faculty; research is limited; educational materials and facilities are of poor quality and academic programmes do not meet modern requirements” (p. 18). By tapping the best African and global academic resources, by improving connectivity in African Virtual University (AVU) learning centers and host universities, and by serving as a catalyst for new economic development, the 
AVU hopes to increase access to tertiary and continuing education in Africa. I think that the list of lessons learned is most useful, such as the problem of obtaining international accreditation for the AVU's curriculum, teaching methods, and delivery modes. There is also a good list of challenges that hinder the implementation of AVU programs, such as high communication costs and the necessity for a communication policy that can serve as a warning to those involved in similar efforts.

David Murphy and colleagues review "Continuing Professional Education Across Borders" in Chapter 3. After outlining three case studies, the authors draw some conclusions regarding lessons learned from these cases. One commonality stated was that, regardless of whether starting from scratch or repurposing exiting materials, the design and development of the courses needed to be of high quality. Secondly, student support was indicated to be a key to success. Thirdly, a systematic approach to continuous improvement was mentioned as a pathway to success. Feedback from students helps keep courses relevant and timely.

Vivien Martin, in Chapter 4, described an international project concerning the transfer of competencies in the healthcare field. Martin interviewed students, line managers, and tutors to gather multiple perspectives on what was effective and what could be improved in the training being implemented. Not surprisingly, one of the key difficulties for participants was the struggle with the shortage of time. Research conducted recently (Muilenburg and Berge in press) concerning students' perceived barriers to online learning found "lack of time and support for studies" as one of the factors both statistically and practically significant. Tutors helped students overcome these barriers through such efforts as psychological support, motivation, and summarizing key points to focus on. The author cautions that "learning materials have embedded values and assumptions that arise from the culture in which they were developed." These may be appropriate to other learning environments and cultures, but if they are not, it is difficult to disassociate them from the fabric of the already developed materials.

\section{VET Using Distance Learning at the National Level}

Chapters 5-8 turns the spotlight on national public policy programs. Models from Canada, Australia, the Commonwealth of the Pacific nations, and South Africa are examined. These countries have been proactive in setting an agenda for their vision for distance education in VET. Irene Lewis uses Chapter 5 to outline the Canadian need for alternative delivery of education and training. Given the geographic size of Canada, a coordinated educational transformation has been necessary over the past several decades. Part of the vision espoused is that learning is controlled by the learner. Technology is an important part of facilitating change to a culture of lifelong learners. McClenney (1998) reminded us:

Cultural change is extremely difficult and usually politically hazardous. It takes a long time and a sustained commitment. It means addressing values, expectations, priorities, sacred cows, the very identities of people and institutions. It is far more likely to occur in response to crisis than in response to a golden opportunity. This cultural change is a profound shift from a focus on the needs of faculty and administrators to a focus on the needs of students and other customers. It is a 
shift from a culture of entitlement to a culture of performance, from a culture of anecdote to a culture of evidence. It is a shift from a model focused on student and community deficiencies to a model presuming potential and capacity. Most importantly, it is a shift from teaching to learning (emphasis in original, n.p.).

Governments are setting policy to provide access to learning throughout Canada that will strengthen economic productivity and increase global competitiveness (p. 83).

In Chapter 6, Phoebe Palmieri discusses the “Australian Flexible Learning Framework.” The two overarching goals of the framework are to encourage accelerated use of flexible learning modes, and to position Australian VET as a world leader in applying information and communications technology (ICT) to vocational education. To do this, the framework articulates five goals that address the professional development, infrastructure, the development of online materials and services, creation of a supportive policy environment, and construction of a supportive regulatory environment. Additionally, these goals are guided by seven principles:

- Shared benefit to all states and territories

- Strategic use of new learning technologies

- Accelerated take-up of flexible-learning methodologies

- Strategic partnerships between VET agencies and other public-sector agencies and the private sector

- Leveraged investment of national funds

- Maximizing employee involvement in Framework projects

- $\quad$ Projects driven by client demand (p. 86.)

While this framework is well planned, there are challenges that continue to prove troublesome. For instance, the lack of involvement of industry in the planning efforts so far and the inability to modify policy in all areas called for by the framework. Sustainability is one of the watchwords Bartram, Lene and Williams (Chapter 7) discuss in their description of distance learning for VET in the island states in the Pacific. Their estimation of what is required to sustain distance learning include leadership and coordination within the governments involved, skilled personnel who can develop and deliver distance learning courses in VET, and policies directed on online learning initiatives.

With regard to South Africa, Ginger Bester argues (Chapter 8) that the lingering effects of discriminatory policies based on race still suppresses political, economic and social development (p. 113). The economic development of the whole country is hampered by a largely unskilled labor force. The shortage of skilled labor stifles the country's ability to successfully compete globally despite their enormous potential. The author believes that a successful VET program can play an important role in the overall human capital development objectives of government.

The increased attention that open learning is receiving in South Africa is based on a perspective that includes learner-centeredness, lifelong learning, flexibility, cost effectiveness, expectations of success, and learner support. It also is approached by seeing what barriers to learning can be 
removed from the learner's pathway. These include such things as geographical isolation, discrimination based on race, gender, age, or physical disability, the inability to take time off work for training, lack of 'appropriate' qualifications, and lack of the funds that restrict [student] access to educational opportunities” (p. 119). It becomes clear that organizations, approaches to learning, and existing management systems and policies will need to change pushed by the widespread changes in South African society.

There is a key issue as to whether a more comprehensive and systemic approach is required that links policy for the formal education system and for the adult community in synergistic ways so that outcomes are value added. Such an integrated and holistic approach would require further progress towards whole-of-government collaboration across the levels of the Australian federal system, and innovation in developing arrangements to bring about these outcomes. Achieving the full potential of ICT in education and in society, so as to transform the way people learn in the digital era, is likely to require policies that stimulate cultural change in education institutions, and in the communities they serve, in building a culture that supports enterprise, learning, innovation, and creativity (Kearns and 2002).

A similar vision seems to permeate the South African policies as described by Bester.

\section{VET and Distance Learning at the Organizational Level}

The third section of the book focuses on policy implications at the institutional level, with the contributors explaining educational models and policy issues that organizations must address when using distance education for VET. The issues range from "educational policy directions and choices about structure, organization and systems, to questions of program design and choice of delivery technologies appropriate ... the needs of the learners” (p. 125).

VET in the United Kingdom, using open and distance learning, is addressed by Sargant in Chapter 9. Sargant briefly describes several of the institutions that have been key to educational reform in VET: the Open University, the Open Tech, the Open College, and the University for Industry. The author points out that most of these initiatives have been government sponsored, and so several challenges are inherent regarding funding cycles, and the control or interference that the government may place on the organization. Additionally, there is a conflict between the economic goals of most organizations for each project, and the social goals the government may have for these same projects (p. 144).

Yoni Ryan describes the private sector model in the United States (Chapter 10). The author argues, and in many cases reiterates previous contributors, that there is a confluence of factors affecting VET such as:

- The shift from manufacturing to service industries and the consequent demand by employers for education and training beyond the K-12 level

- Gobalized industries made possible by new ICTs 
- An ideological shift to a more "market-driven” educational system from state provision of basic services in education and training

- An increased acknowledgement of the merit of student-centered education that shifts the focus of the educational experience to the learner and away from the teacher-expert and the subject of study (p. 147-148).

In other words, a manifestation of higher tuition, more flexible learning, more distance learning, and more focus on performance-based learning.

Peter le Cornu and colleagues (Chapter 11) examines VET institutions using three case studies, one each in Scotland, South Africa, and Kenya. The three are certainly different contextually, but have common traits that lead to their success. From the institutional perspective, there must be a clear vision for open and distance learning and the benefits it will bring to the table. Stakeholders must be convinced that high-quality programs in open and distance learning, meet the needs of the students. Noted to be of critical importance here and in many other chapters is the need for learning support. Finally, organizations that want to implement open and distance learning for VET must make sure that their administrative systems support the implementation of flexible forms of learning.

Mini-cases in Chapter 12 are from Mongolia, Bangladesh, and Australia. Haughty and her colleagues use these cases to discuss cooperation and partnerships, media choice, and skills-based training, and training designs. The authors also highlight blended learning that is - of a mixture of online and in-person delivery - as an effective means to increase retention and student satisfaction with the learning experience. While there may be validity to this approach at the present time, I am not sure I would endorse a hybrid type of learning on a wholesale basis. More on this below, but for now let me just say that blended learning may blend some of the least desirable characteristics in a learning environment, especially from the sponsoring organization's perspective.

\section{Conclusions}

In the last section of the book, Chapter 13, Greville Rumble and Louise Moran draw conclusions regarding "Policy Frameworks for VET in an Electronic Age." The editors note that one of the obstacles to open and distance education is the variability in the quality of and access to the communication infrastructure across the world. To this, add the lack of computers in many homes worldwide and lack of access is an important consideration to policy makers.

The editors speculate that while technology-based learning will increase, some form of blended (i.e., hybrid, mixed-delivery) will be settled on at the end of the day. I suspect they are correct. The editors also point out, however, elsewhere in this chapter that the more student support is given, the more direct student costs rise (i.e., reducing economics of scale hoped for by administrators). Since high levels of student support is found by authors in this book to be an important factor leading to student satisfaction and retention, it would seem that adding an online component to an in-person program will probably dramatically increase costs if the program is 
successful. Add to this the notion that while many students want the convenience that open and distance learning provides, they do not want to give up their in-person learning environment. Would not these factors indicate the possibility of a blending of the worse of both delivery modes?

Overall the book is well worth a careful read by anyone involved in the policy aspects of open and distance education, especially those who are involved in VET. Rumble and Moran state that what they "hope for from this book is that policy-makers, at whatever level they work, will gain a better appreciation of the factors that make for success" (p. 224) in VET through open and distance education. They surely have accomplished that.

\section{References}

Berge, Z. L. (2004). Complexity and confusion in distance education. Distance Learning. 1(2): 16.

Gellman-Danley, B., and Fetzner, M. J. (1998). Asking the Really Tough Questions: Policy issues for distance learning, Journal of Distance Learning Administration, 1(1). Retrieved January 17, 2005 from: http://www.westga.edu/ distance/danley11.html

Kearns, P., and Grant, J. (2002). Learning, Technology, Community, Partnership: A report on Australian policies for information and communication technologies in education and training. Australian Government: Department of Education, Science and Training. Retrieved January 14, 2005 from: http://www.dest.gov.au/highered/otherpub/aust_ict_report.pdf

Kruse, K. (2003). The benefits and drawbacks of e-learning. e-LearningGuru.com. Retrieved January 13, 2005 from: http://www.e-learningguru.com/articles/art1 3.htm

Massy, W., and Zemsky, R. (2003). The pros and the cons. Retrieved January 13, 2005 from: http://www.nwlink.com/ donclark/hrd/elearning/proscons.html

McClenney, K. M. (1998). Community Colleges Perched at the Millennium: Perspectives on innovation, transformation, and tomorrow. Leadership Abstracts, 11(8). Retrieved February 23, 2005 from: http://www.league.org/publication/abstracts/leadership/labs0898.htm

Muilenburg, L. Y., and Berge, Z. L. (in press). Student Barriers to Online Learning: A factor analytic study. Distance Education: An International Journal.

ThinQ Research Department. (n.d.). How e-learning can increase ROI for training. ThinQ White paper. Retrieved January 13, 2005 from: http://whitepapers.zdnet.co.uk/0,39025945,60024909p-39000612q,00.htm 
W.R. Hambrecht \& Co. (2001). eLearning: A key strategy for maximizing human capital in the knowledge economy. Primelearning.com White Paper. Retrieved January 17, 2005 from: http://www.primelearning.com/approach/pdf/maximizinghumancapital.pdf

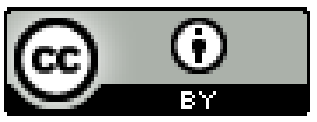

